\title{
Constraint Analysis and Optimization of NES System Based on Variable Pitch Spring
}

\author{
Zhenhang Wu, Manuel Paredes ${ }^{(\bowtie)}$, and Sébastien Seguy \\ Institut Clément Ader UMR CNRS 5312, Université de Toulouse, UPS, INSA, \\ ISAE-SUPAERO, MINES-ALBI, CNRS, 3 rue Caroline Aigle, Toulouse, France \\ paredes@insa-toulouse.fr
}

\begin{abstract}
This study proposes the realization of a device with a pure cubic stiffness mechanism to suppress a wide range of vibrations, which is known as the Nonlinear Energy Sink. Deciding how to construct a light, reliable NES device is always a challenge. According to our design, the device can counterbalance the undesirable linear stiffness that emerges from the intrinsic property of a variable pitch spring. Our goal is to reduce the mass of the spring while keeping the same cubic stiffness. Through the multifaceted analysis of the nonlinear constraint, we try to explore the full potential of NES device to reduce its mass. Meanwhile, a global search method, Multi Start, is applied by repeatedly running a local solver. Finally, a new design with different variable pitch distribution is proposed.
\end{abstract}

Keywords: Nonlinear Energy Sink (NES) · Variable pitch spring · Constraint analysis · Multi Start method

\section{Introduction}

Vibration is an inevitable phenomenon and can be harmful to structures in the domains of civil engineering or the machine industry. In recent decades, novel systems composed of a primary linear structure and a strongly nonlinear attachment have attracted attention because of their ability to absorb a wider range of vibration frequencies and their relatively small attached mass [1]. Because of the existence of a nonlinear component, which is always referred to as cubic stiffness, the system demonstrates localization and irreversible transient transfer of energy from the primary system to the attached mass [2]. This new concept is called a Nonlinear Energy Sink (NES). Several methods have been proposed for achieving a cubic stiffness. G. Kerschen used a straight air tract to support the primary system and NES. An essential cubic stiffness nonlinearity was obtained by means of a thin hat without tension [3]. Our idea is to use a variable pitch spring to produce the desired cubic stiffness by designing the distribution of the pitch.

The structure of the current paper is as follows. In Sect. 2, a NES system design process will be presented based on the variable pitch spring. In Sect. 3, the nonlinear constraint will be defined according to the various conditions. In Sect. 4, Multi Start, a global search method, will be applied and the optimization result will be compared. Section 5 contains some concluding remarks and discussion.

(C) The Author(s) 2021

L. Roucoules et al. (Eds.): JCM 2020, LNME, pp. 162-168, 2021.

https://doi.org/10.1007/978-3-030-70566-4_26 


\section{NES Design Process}

The most significant component in a NES system is the cubic stiffness, which is obtained through the variable pitch spring in our study. A core characteristic of the variable pitch spring is its progressively increasing pitch, which results in a variable stiffness. Sequenzia $\mathrm{G}$ provides an iterative calculation method to define precisely the geometry of helix line [6]. Another design of a variable pitch spring coupled with a negative stiffness mechanism has been proposed by D. Qiu [5] and used in our study. The objective displacement-force relation of a variable pitch spring can be defined by the following equation, where $k_{0}$ is the linear stiffness before the spring reaches its transition point $s_{t}, a_{l}$ is the spring rate in the nonlinear part, and $a_{3}$ is the cubic stiffness value.

$$
F=\left\{\begin{array}{cr}
k_{0} u & \left(u \leq s_{t}\right) \\
a_{3}\left(u-s_{t}\right)^{3}+a_{1}\left(u-s_{t}\right)+k_{0} s_{t} & \left(u>s_{t}\right)
\end{array}\right.
$$

However, when we apply the nonlinear spring, the force displacement characteristic inevitably includes a linear part [5]. To skip the linear part, a method of combining two pre-compressed springs at the transition point is adopted, as in part (b) of Fig. 1. So the composed stiffness curve $f_{K}=\left(a_{1}+k_{0}\right) u+a_{3} u^{3}$ is obtained. To counterbalance the linear phase $a_{1}+k_{0}$, a negative stiffness mechanism is introduced, as in part (a) of Fig. 1. When the two linear springs are subjected to horizontal pre-compression, they have a negative stiffness in the vertical direction. The force-displacement relation can be expressed as a Taylor expansion. It is important to note that the Taylor expansion is valid only when the displacement remains close to the initial balancing point. By adding the force of the pre-compressed variable pitch spring combined with a negative stiffness mechanism, a composed force displacement relation is expressed:

$$
F=\left(a_{1}+k_{0}-2 k_{l} \frac{l_{p}}{l_{0 l}+2 l_{c}-l_{p}}\right) u+\left(a_{3}+k_{l} \frac{l_{0 l}+2 l_{c}}{\left(l_{0 l}+2 l_{c}-l_{p}\right)^{3}}\right) u^{3}
$$

Here, $l_{0 l}$ and $l_{p}$ are the free length of the linear spring and its length of precompression. $l_{c}$ is the length of the connectors, which are connected to the ground and the central mass by hinges. The connector is marked in Fig. 2. A schematic diagram of this NES system is proposed in Fig. 1. The linear component of Eq. (2) can be counterbalanced by defining the stiffness of cylindrical spring $k_{l}$. To design a cylindrical spring with the target stiffness, the diameter of a linear cylindrical spring, $D_{l}$, and the diameter of its wire, $d_{l}$, are necessary to fix its active number of coils through the following equation:

$$
n_{l}=\frac{G d_{l}^{4}}{8 D_{l}^{3} k_{l}}
$$

A method using a special coordinate point is adopted to manufacture a variable pitch spring with the required stiffness curve. Groups of coils with different pitches are symmetrically distributed on both sides of the spring. The detailed process to determine the distribution of variable pitch can be found in Donghai's work [4]. Through the 
above analysis, the whole NES system is determined by 11 independent variables $(d$, $\left.D, l_{f}, d_{l}, D_{l}, l_{0 l}, k_{0}, a_{1}, s t, a_{3}, p_{c}\right) . p_{c}$ is a dimensionless coefficient of pre-compression $l_{p}=p_{c} * l_{0 l}$. The mass of the total of 4 springs is easily obtained:

$$
M=2\left(\left(\sum_{i=1}^{n_{a}} n_{i}+1.5\right) D \frac{d^{2} \pi^{2}}{4}+\left(n_{l}+1.5\right) D_{l} \frac{d_{l}^{2} \pi^{2}}{4}\right) \rho
$$

The sum of $n_{i}$ and $n_{l}$ are the total numbers of active coils in the variable pitch spring and the cylindrical spring, the extra 1.5 coils being added as end coils at both spring sides to support the active coils. The lower boundary $(L b)$ and upper boundary $(U b)$ of the parameters are presented in Table 1.

Table 1. Lower and upper boundaries for the parameters of the NES system.

\begin{tabular}{l|l|l|l|l|l|l|l|l|l|l|l}
\hline & $d[\mathrm{~mm}]$ & $D[\mathrm{~mm}]$ & $l_{f}[\mathrm{~mm}]$ & $d_{l}[\mathrm{~mm}]$ & $D_{l}[\mathrm{~mm}]$ & $l_{\text {Ol }}[\mathrm{mm}]$ & $k_{0}[\mathrm{~N} / \mathrm{m}]$ & $a_{1}[\mathrm{k} / \mathrm{m}]$ & $s_{t}[\mathrm{~mm}]$ & $a_{3}\left[\mathrm{~N} / \mathrm{m}^{3}\right]$ & $p_{c}$ \\
\hline$L b$ & 0.1 & 20 & $\begin{array}{l}\text { Course } \\
+2 \text { toler }\end{array}$ & 0.1 & 20 & 20 & 100 & 100 & $\begin{array}{l}0.5 \text { Course } \\
+ \text { toler }\end{array}$ & $0.2 e 5$ & 0.3 \\
\hline$U b$ & 5 & 60 & 95 & 5 & 60 & 70 & 800 & 800 & 60 & $8 \mathrm{e} 5$ & 0.6 \\
\hline
\end{tabular}

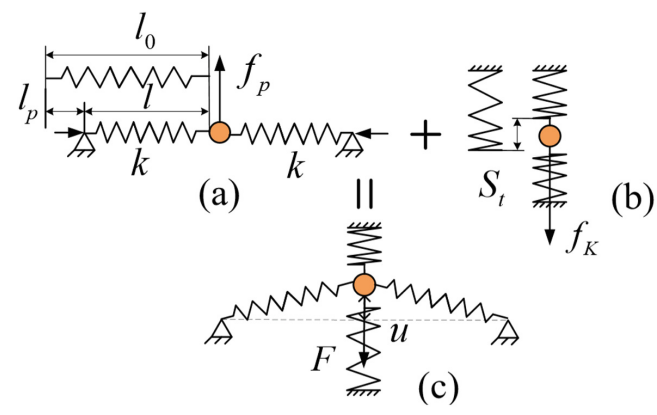

Fig. 1. Schematic of NES mechanism

\section{Nonlinear Constraint Analysis}

In order to maintain reliable operation of the device in complex situations, the design of the spring and the parameter values should be strictly chosen to meet the different constraints, e.g. design constraints, buckling conditions, space between coils of the nonlinear spring, and static maximum constraint. These nonlinear constraints involve all the design parameters, and they can hardly be separated individually. For the sake of convenience, we sort the constraints in Table 2. 
Table 2. Definition of the optimization constraint

\begin{tabular}{|c|c|c|}
\hline No & Description & Constraint \\
\hline 1 & $\begin{array}{l}\text { Avoid the occurrence of negative numbers of coils during the } \\
\text { calculation }\end{array}$ & $k_{0}<a_{1}$ \\
\hline 2 & Ensure the accuracy of the fitting & $n_{a}>8$ \\
\hline 3 & Maintain spring characteristics & $n_{l}>4$ \\
\hline 4 & $\begin{array}{l}\text { Strengthen the spring and induce low internal stress. } \\
\text { Facilitate the manufacturing process }\end{array}$ & $5<\frac{D}{d}<20$ \\
\hline 5 & & $5<\frac{D_{l}}{d_{l}}<20$ \\
\hline 6 & $\begin{array}{l}\text { Ensure spring free length is smaller than its critical length } \\
L_{k}=v_{l} l_{0 l} / D_{l} \text { to avoid buckling. Sitting factor for linear } \\
\text { spring where both ends are connected with hinge joints } \\
v_{l}=1\end{array}$ & $v_{l} \frac{l_{0 l}}{D_{l}}<2.6$ \\
\hline 7 & Sitting factor $v_{n l}=0.5$ for nonlinear spring that is embedded & $v_{n l} \frac{L_{l}}{D}<2.6$ \\
\hline 8 & Constant helix angle of linear spring & $\arctan \left(\frac{p_{l}}{\pi D_{l}}\right)<7.5^{\circ}$ \\
\hline 9 & $\begin{array}{l}\text { The helix angle is variable for the nonlinear spring, its } \\
\text { maximal helix angle is considered }\end{array}$ & $\arctan \left(\frac{\max \left(p_{n l}\right)}{\pi D}\right)<7.5^{\circ}$ \\
\hline 10 & $\begin{array}{l}\text { Ensure the maximum corrected main stress does not exceed } \\
\text { the acceptable maximum stress. Maximum stress: } \tau_{\max }= \\
8 F D \cos (\alpha)(1+2 d /(3 D)) /\left(\pi d^{3}\right) \text {. Stress correction factor } \mathrm{k}= \\
(\mathrm{w}+0.5) /(\mathrm{w}-0.75) \text {. Maximum allowable stress } \tau_{\mathrm{zul}} \text { is equal } \\
\text { to } 0.48 \mathrm{Rm} \text {. For stainless steel } R m=1919-255.86 \ln (d)\end{array}$ & $\tau_{z u l}>k \tau_{\max }$ \\
\hline 11 & $\begin{array}{l}\text { Reduce the risk of a crash under alternating load. Compressed } \\
\text { solid length of spring } l n=d_{l}\left(n_{\text {lin-active }}+1.5\right)+S a \text {. Sum } \\
\text { of minimum spaces between active coils. } S a=n_{\text {lin-active }} \\
\left(0.0015 D_{l}^{2} / d_{l}+0.1 d_{l}\right)\end{array}$ & $l_{p} \leq l_{0 l}-l_{n}$ \\
\hline 12 & $\begin{array}{l}\text { Avoid nonlinear spring } 1 \text { or } 3 \text { being released central mass (in } \\
\text { Fig. } 2 \text { right) }\end{array}$ & $s_{t}>\frac{\text { Course }}{2}+$ toler \\
\hline 13 & & $l_{f}-s_{t}>\frac{\text { Course }}{2}+$ toler \\
\hline 14 & $\begin{array}{l}\text { Avoid the linear spring } 2,4 \text { separation in Fig. } 2 \text { left. Distance } \\
\text { between hinges in extreme position } \\
D_{\text {max }}^{2}=\left(l_{0 l}-l_{p}+2 l_{c}\right)^{2}+\left(l_{f}-s_{t}\right)^{2} \text {, free distance } \\
D_{f}=l_{0 l}+2 l_{c}\end{array}$ & $D_{f}-D_{\max }>$ toler \\
\hline 15 & $\begin{array}{l}\text { Error control. Taylor expansion with higher order term } \\
\Delta \mathrm{F}(\mathrm{u})=0.75 \mathrm{k}_{1}\left(\mathrm{l}_{01}+2 \mathrm{l}_{\mathrm{c}}\right) \mathrm{u}^{5} /\left(\mathrm{l}_{01}-\mathrm{l}_{\mathrm{p}}+2 \mathrm{l}_{\mathrm{c}}\right)^{5} \\
\text { Maximum force } F_{\max }=A_{3}(\text { Course } / 2)^{3}\end{array}$ & $\Delta F(u)<0.05 F_{\max }$ \\
\hline
\end{tabular}


When the central mass moves to the upper maximal displacement, two potentially dangerous conditions appear. The separated position is indicated in the dotted red circle in Fig. 2, which corresponds to the 12th/13th/14th constraints.
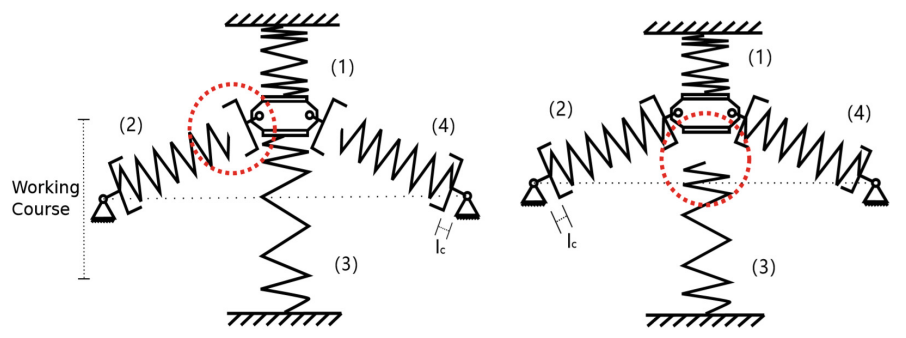

Fig. 2. Detachment conditions (1) left: spring 2, 4 separation; (2) right: spring 1 or 3 released

\section{Optimization Result}

The function fmincon of Matlab is used to obtain a local minimum value with respect to the nonlinear and linear constraint. This kind of nonlinear optimization problem is extremely sensitive to the initial starting point. To generate a global solution, one idea is to repeatedly run a local solver with the various starting points. The best solution is then picked among the multiple local minima. The Multi Start method was applied in our study.

Firstly, we should define the working course, Course $=80 \mathrm{~mm}$, and the tolerance, toler $=5 \mathrm{~mm}$, to prevent the center of mass falling outside the working course. The target cubic stiffness, $A_{3}$ is $4 e 5 \mathrm{~N} / \mathrm{m}^{3}$. The initial value is chosen with the parameters given in [5].

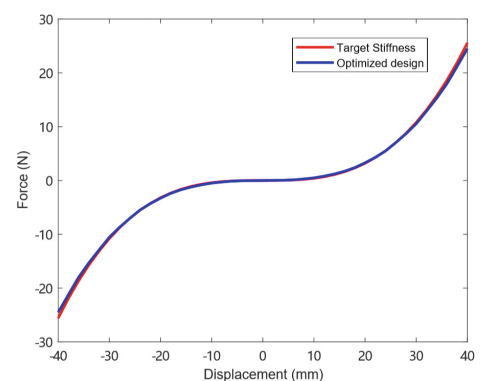

Fig. 3. Comparison of target stiffness and optimized design stiffness.

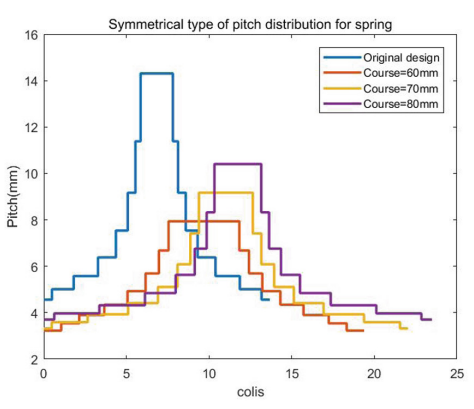

Fig. 4. Symmetrical type of pitch distribution for different optimized designs $(80 / 70 / 60 \mathrm{~mm})$ and original design. 
When the number of local solvers is 1000 , the lightest quality design parameter is obtained in Table 3 and a new distribution of pitch is found in Fig. 4. Our mass is reduced to $88.2 \mathrm{~g}$. So, compared with the original mass of $182.98 \mathrm{~g}$, there is a mass saving of $51.8 \%$. At the same time, the error of the force-displacement relation of optimization $(4.28 \%)$ is kept below the tolerance level $(5 \%)$ presented in Fig. 3. In other side, the different design targets for example Course $=70 \mathrm{~mm}$ and Course $=60 \mathrm{~mm}$ are performed. The mass result reduce to $69.9 \mathrm{~g}$ and $60.3 \mathrm{~g}$ respectively. The detailed optimal parameters are presented in Table 3.

Table 3. Parameter of optimization result for Course $=80 \mathrm{~mm} / 70 \mathrm{~mm} / 60 \mathrm{~mm}$

\begin{tabular}{l|l|l|l|l|l|l|l|l|l|l}
\hline$d[\mathrm{~mm}]$ & $D[\mathrm{~mm}]$ & $l_{f}[\mathrm{~mm}]$ & $d_{l}[\mathrm{~mm}]$ & $D_{l}[\mathrm{~mm}]$ & $l_{0 l}[\mathrm{~mm}]$ & $k_{0}[\mathrm{~N} / \mathrm{m}]$ & $a_{l}[\mathrm{~N} / \mathrm{m}]$ & $s_{t}[\mathrm{~mm}]$ & $a_{3}\left[\mathrm{~N} / \mathrm{m}^{3}\right]$ & $p_{c}$ \\
\hline 1.6 & 25.1 & 90 & 1.71 & 26.9 & 70 & 165.9 & 165.9 & 48.7 & $2.73 \mathrm{e} 5$ & 0.3 \\
\hline 1.5 & 22.2 & 80 & 1.75 & 26.9 & 70 & 185.7 & 185.7 & 40 & $2.58 \mathrm{e} 5$ & 0.3 \\
\hline 1.4 & 20 & 72.7 & 1.87 & 26.9 & 70 & 231.4 & 253.4 & 35 & $2.15 \mathrm{e} 5$ & 0.3 \\
\hline
\end{tabular}

\section{Conclusions}

This article has studied the realization and optimization of a NES system with a variable pitch spring. The main challenge is to construct a pure cubic stiffness system. The variable pitch springs are combined axially with pre-compression and negative stiffness mechanism are used to counterbalance the linear phase and leave a pure cubic stiffness. By using Multi Start method, it is possible to obtain global resolution with respect to the nonlinear constraint and minimize the mass of the system. The stiffness curve of optimized design basically coincides with the target stiffness curve, while the mass is reduced effectively. For the next stage of the study, we will analyze the optimization result and other constraints still further to reduce the number of parameters.

\section{References}

1. Gourdon, E., Alexander, N.A., et al.: Nonlinear energy pumping under transient forcing with strongly nonlinear coupling: theoretical and experimental results. J. Sound Vibr. 300(3-5), 522-551 (2007)

2. Gendelman, O.V.: Transition of energy to a nonlinear localized mode in a highly asymmetric system of two oscillators. Nonlinear Dyn. 25(1-3), 237-253 (2001)

3. Kerschen, G., et al.: Experimental demonstration of transient resonance capture in a system of two coupled oscillators with essential stiffness nonlinearity. J. Sound Vibr. 299(4-5), 822-838 (2007)

4. Qiu, D., Paredes, M., Seguy, S.: Variable pitch spring for nonlinear energy sink: application to passive vibration control. Proc. Inst. Mech. Engi. Part C J. Mech. Eng. Sci. 233(2), 611-622 (2019) 
5. Rodriguez, E., Paredes, M., Sartor, M.: Analytical behavior law for a constant pitch conical compression spring. 5 (2005)

6. Sequenzia, G., Oliveri, S., et al.: A new methodology for calculating and modelling non-linear springs in the valve train of internal combustion engines. SAE Technical Paper (2011)

Open Access This chapter is licensed under the terms of the Creative Commons Attribution 4.0 International License (http://creativecommons.org/licenses/by/4.0/), which permits use, sharing, adaptation, distribution and reproduction in any medium or format, as long as you give appropriate credit to the original author(s) and the source, provide a link to the Creative Commons license and indicate if changes were made.

The images or other third party material in this chapter are included in the chapter's Creative Commons license, unless indicated otherwise in a credit line to the material. If material is not included in the chapter's Creative Commons license and your intended use is not permitted by statutory regulation or exceeds the permitted use, you will need to obtain permission directly from the copyright holder.

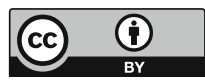

